\title{
Digitalization of motifs: Traditional to contemporary through CAD
}

\author{
Aligina Anvitha Sudheshna and Rupal Babel
}

Received: 26.05.2019; Revised: 10.11.2019; Accepted: 24.11.2019

See end of the paper for authors' affiliations

\section{Rupal Babel}

Department of Textiles and Apparel Designing, College of Community and Applied Sciences, Maharana Pratap University of Agriculture and Technology, Udaipur (Rajasthan) India

Email : babelrupal66@gmail.com
ABSTRACT : Motif is the basic unit of design which plays avery significant role in designing. Each motif has its origin just like a fabric which has its specific origin and sequence. Huge amount of processing is needed for evaluation and to produce variety in shape and size for its finalisation and presentation. In designing process weavers are assigned for weaving process and other embellishment techniques like embroidery, dyeing, printing generatesimaginings of attractiveness using motifs which are acquainted through art, music, literature, religion, environs and from the past on textiles. Improvement in any arena is crucial and on-going process so in the turfs of traditional textiles. For the development of fusion motifs, thirty traditional motifs were selected from both Kalamkari and Bidriware. A total of forty fusion motifs were developed using CAD softwares. Best twenty selected designs were further used onfive home textiles to develop placements to get an overall look of the developed fusion motifs.

KEY WORDS: Motifs, Digitalization, Traditional, Fusion motifs

- HOW TO CITE THIS PAPER : Sudheshna, Aligina Anvitha and Babel, Rupal (2019). Digitalization of motifs: Traditional to contemporary through CAD. Asian J. Home Sci., 14 (2) : 436-438, DOI: 10.15740/ HAS/AJHS/14.2/436-438. Copyright@ 2019: Hind Agri-Horticultural Society. 